\title{
Inuit Attitudes towards Co-managing Wildlife in Three Communities in the Kivalliq Region of Nunavut, Canada
}

\author{
Nils A.A. Lokken, ${ }^{1,2}$ Douglas A. Clark, ${ }^{1}$ Else G. Broderstad ${ }^{3}$ and Vera H. Hausner ${ }^{4}$
}

(Received 12 August 2016; accepted in revised form 5 September 2018)

\begin{abstract}
We explored Inuit attitudes towards co-managing wildlife in the Kivalliq Region of Nunavut, Canada, working in partnership with the hunters and trappers' organizations of Igluligaarjuk (Chesterfield Inlet), Tikirarjuaq (Whale Cove), and Qamani'tuaq (Baker Lake). In mixed-methods interviews, study participants in the two coastal communities described dissatisfaction with polar bear (Ursus maritimus) management outcomes, in contrast to a general satisfaction with (or indifference to) the management of other species. Interviewees expressed concern about grizzly bear (Ursus arctos) and, more prominently, caribou (Rangifer tarandus groenlandicus) populations in Qamani'tuaq, the inland community. Researchers have predicted that conflicts specific to polar bear management could lead to regulations being ignored or even defied and endanger the entire system of wildlife co-management. Our results indicate that dissatisfaction over decisions is specific to polar bear management outcomes and does not necessarily apply to the broader system of wildlife co-management. The results suggest that the Nunavut wildlife co-management system is quite functional: polar bear issues aside, Inuit in Qamani'tuaq, Tikirarjuaq, and Igluligaarjuk are largely content with the current functioning of the wildlife co-management regime.
\end{abstract}

Key words: attitudes; Qamani’tuaq; Igluligaarjuk; Tikirarjuaq; co-management; Nunavut; polar bear; Ursus maritimus

RÉSUMÉ. Nous avons étudié les attitudes des Inuits à l'égard de la cogestion de la faune dans la région de Kivalliq, au Nunavut, Canada, en collaboration avec les organisations de chasseurs et de trappeurs d'Igluligaarjuk (inlet Chesterfield), de Tikirarjuaq (Whale Cove) et de Qamani'tuaq (Baker Lake). Dans le cadre d'entretiens effectués au moyen de diverses méthodes, les participants à l'étude des deux collectivités côtières ont exprimé leur mécontentement à l'égard des résultats de la gestion de l'ours polaire (Ursus maritimus), comparativement à leur satisfaction générale (ou à leur indifférence) quant à la gestion des autres espèces. Par ailleurs, les personnes interrogées ont exprimé des inquiétudes par rapport aux populations de grizzli (Ursus arctos) et des inquiétudes encore plus grandes par rapport aux populations de caribou (Rangifer tarandus groenlandicus) à Qamani'tuaq, la collectivité intérieure. Selon les chercheurs, les conflits en matière de gestion de l'ours polaire pourraient se traduire par le non-respect ou la non-considération des règlements, et mettre en danger le système de cogestion de la faune dans son ensemble. D'après nos résultats, le mécontentement à l'égard des décisions a précisément trait aux résultats de la gestion des ours polaires et ne concerne pas nécessairement le système général de cogestion de la faune. Selon les résultats, le système de cogestion de la faune du Nunavut est bien fonctionnel : mis à part la question des ours polaires, les Inuits de Qamani'tuaq, de Tikirarjuaq et d'Igluligaarjuk sont en grande partie satisfaits du fonctionnement actuel du régime de cogestion de la faune.

Mots clés : attitudes; Qamani’tuaq; Igluligaarjuk; Tikirarjuaq; cogestion; Nunavut; ours polaire; Ursus maritimus

Traduit pour la revue Arctic par Nicole Giguère.

\section{INTRODUCTION}

In a democratic society, the legitimacy of decisions is based on the trust and support of citizens (Putnam et al., 1994; Brondizio et al., 2009). More specifically to the context of wildlife management, support or positive attitudes towards management are thought to be required for conservation success (Heberlein, 2012). Therefore, knowledge about local attitudes towards wildlife management strategies is important to create a base of public trust for successful management (Glikman et al., 2012; Zajac et al., 2012). In Nunavut, Canada, knowledge about the attitudes of local Nunavummiut (the people inhabiting Nunavut, who are dominantly Inuit) towards wildlife management

\footnotetext{
${ }^{1}$ School of Environment and Sustainability, University of Saskatchewan, 117 Science Place, Saskatoon, Saskatchewan S7N 5C8, Canada

${ }^{2}$ Corresponding author: nal.275@usask.ca

${ }^{3}$ Centre for Sami Studies, Faculty of Humanities, Social Sciences and Education, UiT - The Arctic University of Norway, Postboks 6050 Langnes 9037 Tromsø, Norway

${ }^{4}$ Department of Arctic and Marine Biology, UiT - The Arctic University of Norway, Naturfagbygget, Dramsveien 201, 9037 Troms $\varnothing$, Norway

(C) The Arctic Institute of North America
} 
is especially important, in part because wildlife is co-managed by a network of government institutions created by the Nunavut Land Claims Agreement (NLCA) to which Inuit are appointed in representative positions (Armitage and Clark, 2005). Animals are an integral part of Inuit lifestyle and culture, and the constitutionally protected NLCA stipulates that wildlife be co-managed between governments and Inuit organizations. Inuit are hardly "powerless spectators" in this co-management arrangement (Fabricius et al., 2007:5) but interact frequently with wildlife, actively participate in management decisions, and therefore exert considerable control over management outcomes (Suluk and Blakney, 2008). Kotierk (2012:40), for example, argues that public opinion is integral to decisionmaking in the Territory, providing accurate information from which "measurable management goals" can be set.

The Nunavut Wildlife Management Board (NWMB) is the main instrument of wildlife management in Nunavut, with nine appointed members co-managing shared wildlife resources. Although NWMB wildlife management decisions are subject to approval by the responsible minister of the territorial government or federal government, NWMB decisions are usually carried out (White, 2009). The NWMB includes representation from the Government of Canada; the Government of Nunavut; and designated Inuit organizations, including the national Inuit organization, Nunavut Tunngavik Incorporated, and regional Inuit organizations in Nunavut made up of the Kivalliq Inuit Association, Kitikmeot Inuit Association, and Qikiqtani Inuit Association. Harvesting based on NWMB decisions is overseen by hunters and trappers' organizations (HTOs) at the community level and regional wildlife organizations at the regional level. Therefore, Inuit who live in Nunavut and coexist with the wildlife there as part of their traditional lifestyle probably have the greatest stake in management of that wildlife, in addition to considerable power. This relationship is exemplified by contemporary resource management theory, which suggests local people are most invested in local resources and therefore should have more control in management (Berkes et al., 2003). Such an approach is rooted in the principle of subsidiarity, which promotes decentralization and political decision-making at the lowest organizational level possible (Spicker, 1991; Marshall et al., 2007; Berkes, 2010).

The purpose of this study was to document issues in wildlife co-management identified by study participants at the local level in Nunavut. To better understand community members' attitudes towards wildlife management and what they might mean for on-the-ground implementation of wildlife co-management in Nunavut, we explored Inuit attitudes to co-managing wildlife in the communities of Igluligaarjuk (Chesterfield Inlet), Qamani'tuaq (Baker Lake), and Tikirarjuaq (Whale Cove), Nunavut (Fig. 1). The research was undertaken as part of TUNDRA (2018), an international collaborative project investigating relationships between ecosystem services and governance across the Arctic. More specifically, our research fits into the scope of a section of TUNDRA that seeks to understand local peoples' observations about wildlife management and decision-making processes.

Defining attitudes towards wildlife co-management in Nunavut can be very complicated amid multiple and sometimes adversarial perspectives on topics including, but not limited to, caribou populations (Rangifer tarandus groenlandicus), resource development, maintaining hunting of large carnivores such as polar bear (Ursus maritimus) and grizzly bear (Ursus arctos), and ambivalence about a relatively new governance regime (the NLCA and the associated co-management system were passed by the Canadian Parliament in 1993, and Nunavut was established as a Canadian territory in 1999). Despite the complexity presented by the wildlife co-management regime in Nunavut, during data collection we were struck by the consistently strong negative responses to polar bear management. In this region, polar bears have been intensively studied, and the results of that research have been used to justify harvest quota reductions despite the objections of communities that bears remain abundant (Tyrrell, 2007; Dowsley and Wenzel, 2008; Nirlungayuk and Lee, 2009). The resentment felt by communities because of these quota reductions has resulted in a perceived threat to the wildlife co-management system (Clark et al., 2009) and concern that species-specific controversies could lead to generally reduced cooperation and regulations being ignored or even defied (Mallory et al., 2006; Tyrrell, 2007; Clark et al., 2008; Suluk and Blakney, 2008; Dowsley, 2009; Kunuk and Mauro, 2010; Dale and Armitage, 2011). As described previously, quotas based on NWMB decisions are allocated to regions and then ultimately to community HTOs, which implement harvesting. This paper focuses on understanding the apparent effects of the management controversy on community members' attitudes towards wildlife management. We then examine what our findings may mean for the ongoing implementation of wildlife co-management in Nunavut.

\section{METHODS}

\section{Establishing Research Relationships}

Potential participant communities were selected as part of the broader international TUNDRA project to maximize contrasts in socioeconomic conditions and opportunities for wage income between mainland Arctic communities in Canada, Russia, Norway, and the United States (Alaska). In Canada, the HTOs and communities of Igluligaarjuk, Qamani'tuaq, Tikirarjuaq, and Kangiqtiniq (Rankin Inlet) were invited to participate (Fig. 1). The HTO in each community was chosen as the main contact because of the central role these organizations play in resource management at the community level. In March 2013 the authors and TUNDRA project leaders visited the chosen Nunavut communities to discuss the project with 


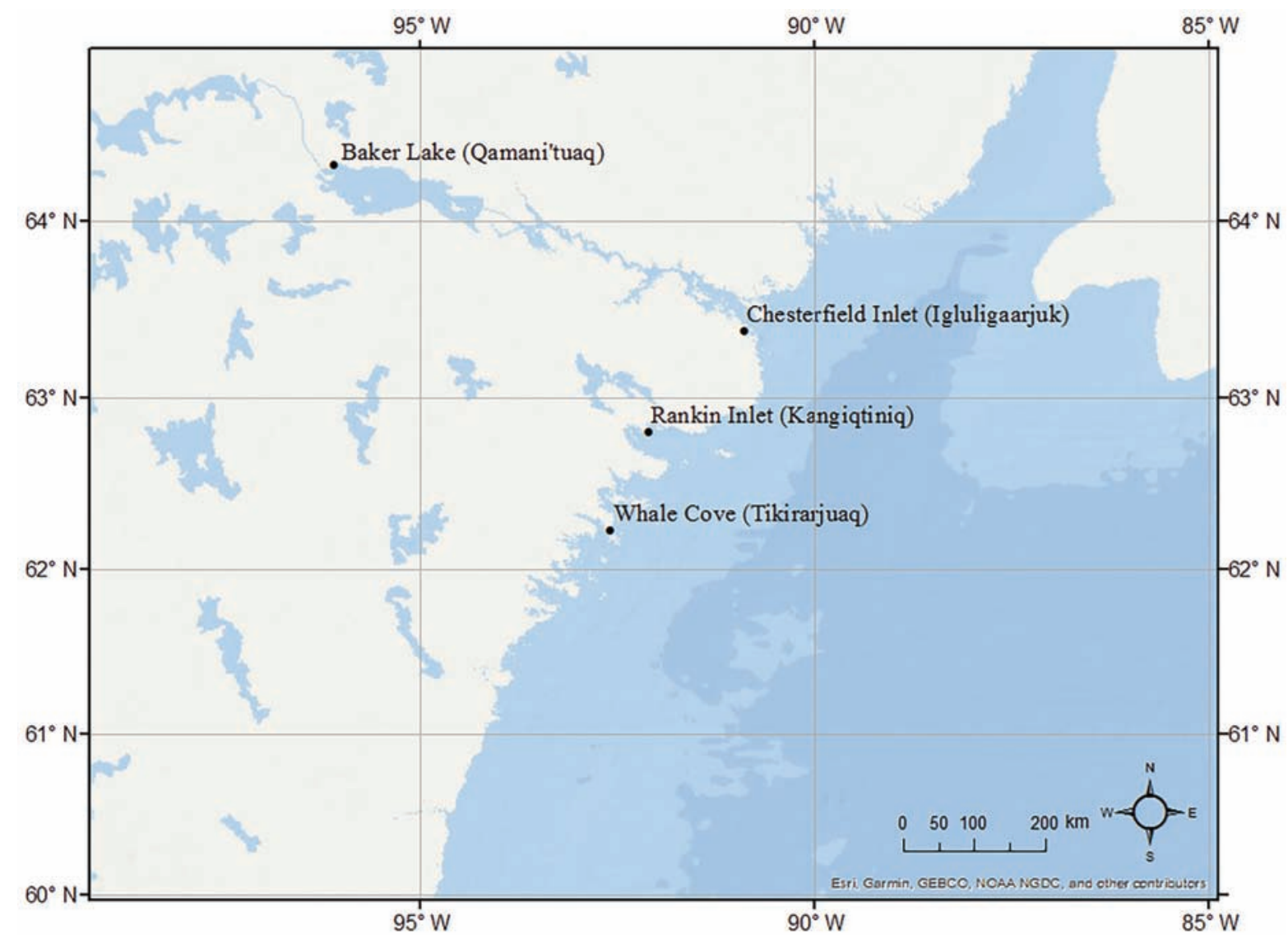

FIG. 1. Locations of participating western Hudson Bay communities: Qamani’tuaq, Tikirarjuaq, and Igluligaarjuk.

the HTOs of each community and with any interested community members. The purpose of these preliminary visits was to determine whether the community HTOs were interested in participating and to find out what the communities would like to see happen with the project and what information could be collected. The HTOs of Igluligaarjuk, Qamani'tuaq, and Tikirarjuaq expressed interest in TUNDRA. Once their intent was confirmed, a Social Science and Traditional Knowledge Research Licence from the Nunavut Research Institute was granted and approval was obtained from the University of Saskatchewan Behavioural Research Ethics Board. Before any data collection was conducted, the HTO of each community confirmed that interviews were the best way to gather the information and that the interview questions were appropriate. A research agreement was also drafted and signed with each HTO, specifying how research would be carried out, how the data would be used, and how the research would be returned to the communities.

\section{Communities}

The communities that participated are all in the Kivalliq Region of Nunavut. In all three of these small, fly-in communities, the population is predominantly Inuit, and Inuktitut is the primary language spoken, although many people also speak English. Based on 2016 census data, population estimates for Igluligaarjuk, Tikirarjuaq, and Qamani'tuaq are 437, 435, and 2069, respectively (Statistics Canada, 2017). The communities that were selected are typical of Arctic areas, where fewer than 500 people reside in many of the communities (Fauchald et al., 2017). Subsistence harvest of animals and use of the land is common and important both as a source of food and for cultural identity in all of the communities. Both Tikirarjuaq and Igluligaarjuk are located on the coast of western Hudson Bay, while Qamani'tuaq is the only inland community in Nunavut and is located on the shores of Baker Lake. Qamani'tuaq therefore has relatively limited access to sea mammals, which makes caribou very important and polar bears not nearly as important. There is also active mining production and exploration near this community.

\section{Cross-Cultural Comparisons}

The participating Canadian locations were a part of a cross-cultural comparison of 28 pan-Arctic communities. Researchers used a mixed-methods interview guide in analyzing reflections of resource users and local decision makers on their experiences and perspectives of Arctic change and resource governance (Brannan, 2005; Frels and Onwuegbuzie, 2013). We intended to document the needs, priorities, and knowledge of Indigenous and 
local residents who were actively involved in wildlife management. Mixed-methods interviews are distinguished from semi-structured interviews in that they supplement open-ended questions and qualitative interpretations with quantitative instruments that allow for comparison across cases. A cross-cultural comparison of 28 cases depends on consistency of questioning, and the use of quantitative instruments and simple frequency statistics allows researchers to record varied perspectives and priorities. The interview protocol therefore combined the use of closed- and open-ended questions to systematically note similarities and differences in responses, while allowing participants to explain their responses through face-to-face dialogues, thereby providing more thorough insights.

All countries participating in the TUNDRA project used the standardized mixed-methods interview guide developed iteratively by the project steering committee. The guide comprised three sections: 1) landscape connection, 2) harvest and local management of ecosystem services, and 3) local influences governing interactions. For the communities in Nunavut, the interview guide was modified after the initial visits to fit the local governance structure, natural environment, and community interests (the complete interview guide is available from the authors on request). Modifications to the guide consisted of adding questions specific to Nunavut that were not included in the overall project or adjusting questions to fit the local context while still maintaining a consistent structure. The first author conducted interviews from June to August 2013.

\section{Sampling of Participants}

Cross-cultural comparison depends on a similar sampling strategy in each community with respect to the target population, sample size, and recruitment strategy (Robinson, 2014). This study focused on a subset of the community that is or has been actively involved in wildlife harvesting or resource management. Random selection of participants was not feasible because many people in the communities had not been directly involved in formal wildlife or resource management beyond a harvester role. Therefore, we used quota sampling to select participants who differed with respect to leadership (elders and those formally engaged in wildlife management), gender, and age. We recruited a minimum of 16 participants in each community with the help of the HTO and from connections made in the community while we were staying there. Nonrandom sampling precludes us from knowing whether our results could be generalized to the community level, but our results reflect the opinions of people who are highly engaged in subsistence activities, as well as elders and leaders in the three communities.

\section{Data Collection and Analysis}

Using the modified TUNDRA interview guide, researchers interviewed participants in a respectful and open manner based on informed consent and guided by community consultation (ACUNS, 2003). Participants signed a consent form written in Inuktitut that informed them about the project and their rights in the study. Each participant received a $\$ 100$ honorarium. The HTO chose Inuktitut translators and made them available for unilingual participants. Interviews were audio-recorded with permission.

Although data gathered from the TUNDRA interviews included many sections and question types, here we focus on a specific subset of responses to categorized closed- and open-ended questions related to wildlife management (Questions 25, 26, and 44 from the Nunavut TUNDRA interview guide, included in Appendix 1). Often, participants also expanded on their responses to the closed-ended questions. Open-ended questions were categorized based on themes that arose in the responses. For example, in question $44 \mathrm{a}$, to determine attitudes towards the presence of polar bears around the community, participants were prompted with the statements that polar bears are dangerous, a nuisance (annoying), or not an issue. For questions $44 \mathrm{~b}$ and $44 \mathrm{c}$, related to management of large carnivores, responses about quotas and whether to increase or remove them arose in responses without prompting and were subsequently categorized. Our analysis therefore incorporates a mixed-methods approach with quantitative analysis of both responses to categorized closed-ended questions and manually organized responses to open-ended questions. We then support our analysis with participants' rich, detailed comments to gain insights into the differences and similarities in responses among participants. We used a statistical analysis of contingency tables in conjunction with simple proportions and participant comments to interpret results. A statistical analysis was conducted using the Wilks's theorem likelihood ratio test to determine whether there were differences in satisfaction with wildlife management of various terrestrial species in the three communities. We used Fisher's exact test to assess attitudes towards the presence of polar bears around the community and whether these bears were considered dangerous or just a nuisance. Opinions about wildlife populations and methods of polar bear management are presented as proportions that indicate how participants responded. In support of the quantitative analysis, researchers selected comments from the interviews that best helped to illustrate attitudes in these three communities.

\section{Verification and Reporting Back}

In June 2014, following preliminary data analysis, we presented initial results to HTOs, study participants, and interested community members. Our presentations had been advertised on the radio and through posters to reach as many community members as possible. HTO attendance at all the presentations was strong, and community representation was especially strong in Tikirarjuaq. The presentations focused on the results the communities had 
identified as most important: wildlife management and human-wildlife conflict, governance at the local level, and other results from TUNDRA that described systems of wildlife management throughout the circumpolar Arctic. These presentations were a process of verification known as "member checks" (Creswell, 1998:202) where community members provided feedback and indicated whether the results were represented accurately. They also offered an opportunity for us to inform the HTO and study participants about the results and about findings from the other countries involved with TUNDRA. We left copies of interview recordings, completed interview guides, and maps, as well as results and translated summaries of the results, with each HTO to be archived and readily available to community members. Reporting the findings to communities proved to be a very important part of the research process - both to ensure valid representation of the data and to maintain relationships and community support for the research. Further discussion of human-polar bear conflict took place at a follow-up workshop that included members of the participating coastal communities (Ewins et al., 2016).

\section{RESULTS}

The first author conducted 50 interviews overall (16-18 per community), 19 of which required translation. Twelve participants were female, 38 were male, and all self-identified as Inuk. We offered the opportunity for anonymity, as per the University of Saskatchewan Behavioural Research Ethics Board's approved protocol for this research, but most participants indicated that they wanted quotations attributed to them by name. Participant ages ranged from 21 to 84, with an average age of 58 . Interview times averaged approximately 2.5 hours but ranged from 45 minutes to six hours.

\section{Satisfaction with Wildlife Co-Management}

Participants were asked what they thought of the management of various species of commonly harvested terrestrial animals, as well as polar bear (Fig. 2). Between $25 \%$ and $50 \%$ of participants, depending on the community, indicated they were satisfied with management for all the species inquired about, excluding polar bear. In the coastal communities, which are closest to polar bear habitat and where polar bear management is therefore most important, only $11 \%$ in Igluligaarjuk and $6 \%$ in Tikirarjuaq indicated satisfaction with the management of polar bear. Excluding polar bear, $0 \%$ and (rarely) up to $19 \%$ of participants indicated dissatisfaction with management for all species, while $61 \%$ and $81 \%$ indicated dissatisfaction with polar bear management in Igluligaarjuk and Tikirarjuaq, respectively. The likelihood ratio test using Wilks's theorem confirmed that in both Igluligaarjuk and Tikirarjuaq, where many participants expressed dissatisfaction about polar bear management, the differences in satisfaction with management of species were significant $(p=0.032$ and $p=0.00$, respectively). In Qamani'tuaq, where polar bear management is not an issue, differences in satisfaction with wildlife management were not significant $(p=1.00)$.

\section{Dissatisfaction and Polar Bears}

Based on our results, by far the most controversial species in the two coastal communities (Igluligaarjuk and Tikirarjuaq) was polar bear (Fig. 2). Participants' comments help to illustrate the dissatisfaction with polar bear management and reasons for that dissatisfaction.

The polar bears, they should leave them alone and give us the tags back. Like for example when polar bears come around, you can't shoot them, but when you're sitting in an office, you don't see that ... locals take care of that themselves.

Anson Kigusiutnar

The question is who owns the bears? Nobody. Jackie Napagok (translated)

People from other countries are controlling the management of polar bears based on what they hear. People who have never seen a polar bear are trying to control them.

Joseph Issaluk (translated)

While this issue is most important to the coastal communities, three participants in Qamani'tuaq also expressed concern about polar bears coming into town and inadequate quotas on the coast. Attitudes towards polar bear management on the coast clearly differ from those towards other species. Many who expressed satisfaction with management of other species indicated dissatisfaction with polar bear management. As well, of the participants who, when asked about management of other species, did not respond, did not know, or did not think management was applicable, many indicated dissatisfaction with polar bear management. The potential significance of nonresponses or don't know responses for other species could be interpreted in various ways. Participants may simply not have known about management for those species about which they did not respond. Participants who expressed an opinion about polar bear management but did not respond for other species may not have thought that management of the other species was important or that it affected them. In the comments, some participants indicated that they did not think some species were managed. Since there is no regulation of some of the species, participants may also not see any management of those species in action.

Participants were also dissatisfied with polar bear population numbers. In Igluligaarjuk and Tikirarjuaq, respectively, $50 \%$ and $38 \%$ of participants indicated there were too many polar bears and a decreased population 


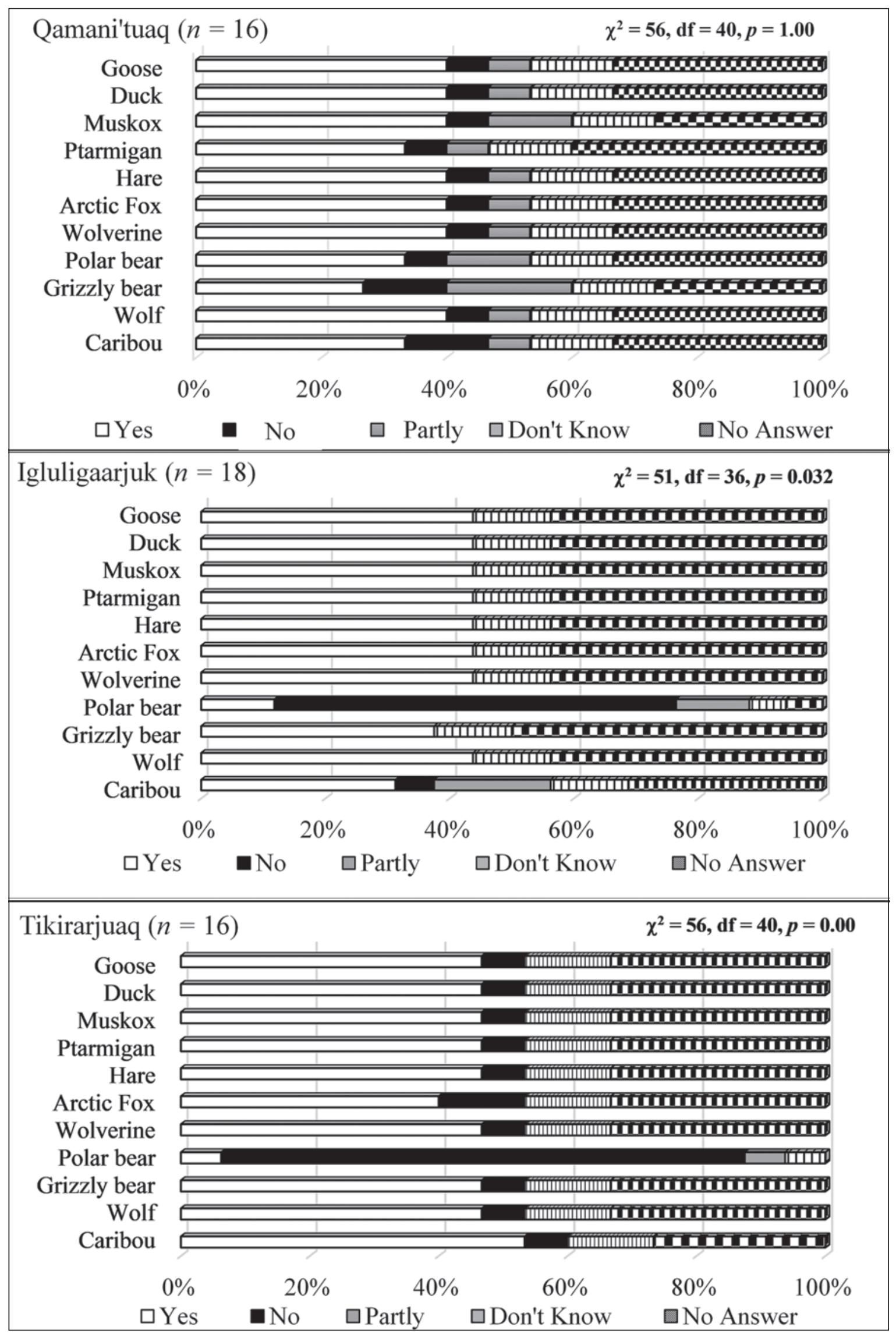




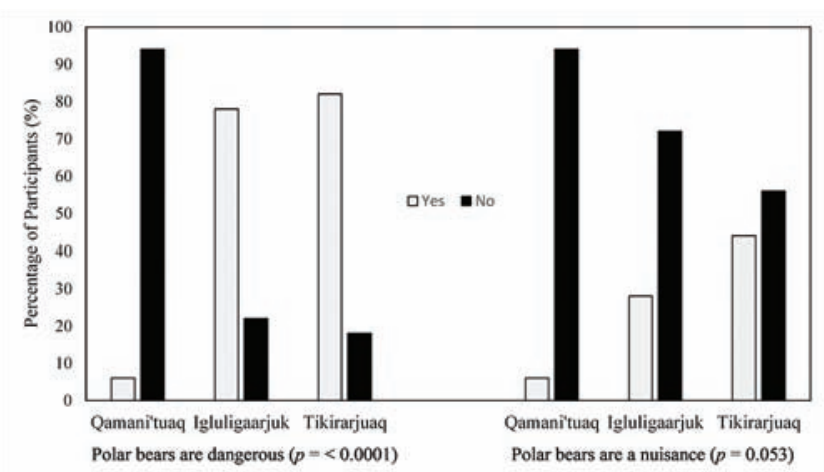

FIG. 3. Opinions about polar bears from respondents in Qamani'tuaq, Igluligaarjuk, and Tikirarjuaq. Fisher's exact test was used to gauge attitudes towards polar bears around the community and the proportion of the participants who thought the bears were considered dangerous or just a nuisance.

would be desirable, while the remaining participants who provided responses indicated the population was satisfactory. In contrast, for all of the other species, between $0 \%$ and $22 \%$ of participants indicated that a decrease in species populations would be desirable. Dissatisfaction with polar bear populations is directly related to the danger posed by polar bears around town, as exemplified by the comment and results below.

Many participants in Igluligaarjuk and Tikirarjuaq viewed polar bears as dangerous or even a nuisance (Fig. 3). Fisher's exact test showed that significantly more participants viewed polar bears as dangerous $(p=0.0001)$ than saw them as only a nuisance $(p=0.053)$. In their comments, participants indicated that the specific problems were more bears coming around town or coming in when the ice melts (Fig. 4).

Used to camp out a lot in the spring in tents. But don't really go camping so much anymore because of polar bears. Can't even stay in small cabins anymore because of fear... Never used to see polar bears in the community, but now come into the community all the time... Now the bears go inland, never used to go inland.

Mary Nangmalik (translated)

The majority of participants in Igluligaarjuk and Tikirarjuaq specifically indicated that either polar bear quotas should be increased or the quotas should be removed (Table 1). Some participants in each of the coastal communities blamed the quotas for an overly high polar bear population while, in contrast, one participant actually suggested that more bears may be killed because of quotas because there is pressure to hunt when you have a tag. Other participants voiced concerns about polar bears killed in defence being counted as part of their allotted quota. There was also some isolated support for maintaining quotas, and two participants in Igluligaarjuk indicated that the system was working well and should not be changed.

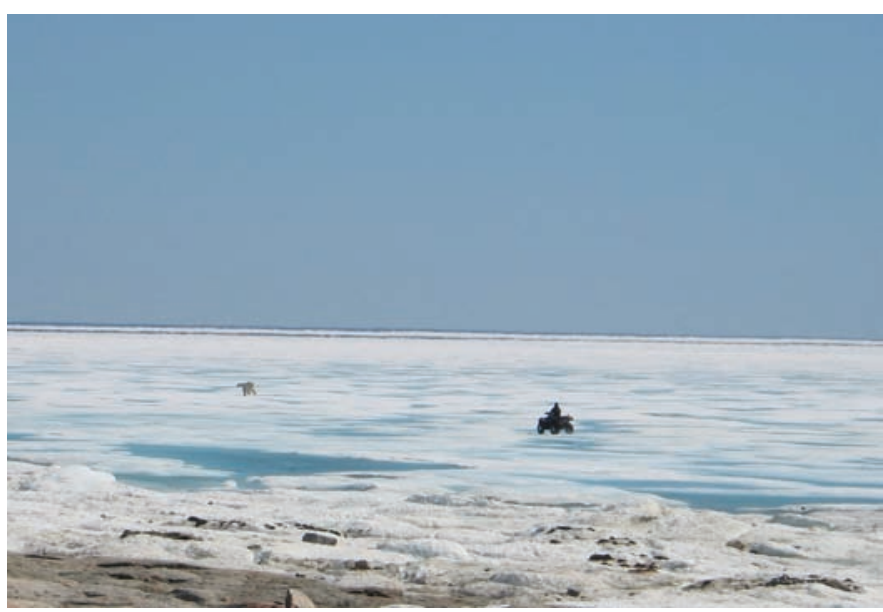

FIG. 4. Polar bear being chased from Igluligaarjuk, June 2014. Photo credit: Nils Lokken.

A demographic difference existed between the participants in the coastal communities who thought polar bear quotas should be removed and those who thought quotas should just be increased (Table 2). In coastal communities, participants who favoured removing quotas completely (as opposed to increasing them) were more likely to be over 60 years old. Similarly, a higher proportion of the participants from the first group had no formal education, whereas in the second group, secondary or higher education was much more common.

\section{Caribou and Grizzly Bears}

Although the differences in opinion are not as pronounced as on the subject of polar bears, participants in each of the study communities expressed concern about caribou and grizzly bear populations in their responses. The questions from which the following results were derived are specific to opinions about wildlife populations and are distinct from questions related to opinions about wildlife management, although participants often commented on wildlife management after answering the initial question.

Two $(11 \%)$ participants in Igluligaarjuk, four $(25 \%)$ in Tikirarjuaq, and seven (44\%) in Qamani'tuaq expressed some concerns about caribou populations when they were asked about wildlife populations. Participants who indicated that there were changes in the caribou migration patterns or population often attributed these changes to a changing climate or to caribou staying away from settled areas and being displaced by aircraft, mining, and exploration activities. They acknowledged the benefit of jobs and income that mining provides in all of the communities, but expressed concern about the impact on caribou and caribou hunting. The following comment illustrates this position.

Our culture is entirely dependent on caribou in this area ...I am trying to think of a way to tell the Government of Nunavut that they cannot be too focused on money and development and keep pushing the resource 
TABLE 1. Opinions about polar bear quotas from respondents in Igluligaarjuk and Tikirarjuaq.

\begin{tabular}{lcll}
\hline \hline & $\begin{array}{c}\text { Igluligaarjuk } \\
(n=18)\end{array}$ & $\begin{array}{c}\text { Tikirarjuaq } \\
(n=16)\end{array}$ & Participant comments \\
\hline Get rid of polar bear quotas & $22 \%$ & $\begin{array}{l}\text { They should be able to get them at all of the seasons...should remove quota on } \\
\text { polar bear...see more bears because of quotas. }\end{array}$ \\
Theresa Kukkiak (translated) \\
$\begin{array}{l}\text { Researchers are saying that polar bears are almost extinct, but I don't believe } \\
\text { this...get rid of quotas, all used in defence kills...with quotas those who get a tag } \\
\text { own an animal, but it shouldn't be like that, the whole community should share... } \\
\text { Inuit lifestyle is not to follow quotas }\end{array}$
\end{tabular}

Quotas OK but need to be increased $\quad 39 \% \quad 56 \%$

The polar bear quota should be increased and Inuks do not waste the polar bear.

Participant 323013

I believe polar bears are increasing in number in this area...I believe the quota should be higher.

Harry Aggark

The polar bears aren't (being managed well)...there's probably not too many, but just never seen this many growing up, and up until ten years ago they were a rare sight. ... when they take our tags away the bears come into town...How come other communities like Coral and Sanikiluaq have larger quotas? This is the western Hudson Bay. They say the most polar bears in the world are in Churchill. Those are our bears, why do we have the smallest quotas?

Chris Jones

Good to have quotas in some areas, but not all...they should increase quotas on polar bear in some areas...they should come here and bear watch for us, look at the number of animals...everywhere they're always saying that we're running out of polar bears, but we're the ones that are here and see it. We're the ones that have the sleepless nights.

Barney Aggark

Never used to be quotas and never used to be any bears around. When the quotas happened, more bears started coming around...The quota should be bigger, but not removed.

Lewis Voisey

TABLE 2. Proportions of participant attitudes towards polar bear quotas and their corresponding demographics.

\begin{tabular}{|c|c|c|c|}
\hline & $\begin{array}{l}\text { Overall sample } \\
\quad(n=50)\end{array}$ & $\begin{array}{l}\text { Get rid of polar bear quotas } \\
\text { (Tikirarjuaq, Igluligaarjuk) } \\
\qquad(n=10)\end{array}$ & $\begin{array}{l}\text { Quotas OK but need to be increased } \\
\text { (Tikirarjuaq, Igluligaarjuk) } \\
\qquad(n=17)\end{array}$ \\
\hline \multicolumn{4}{|l|}{ Age } \\
\hline$>60$ years old & $52 \%$ & $90 \%$ & $35 \%$ \\
\hline$<60$ years old & $48 \%$ & $10 \%$ & $65 \%$ \\
\hline \multicolumn{4}{|l|}{ Education } \\
\hline No formal & $32 \%$ & $40 \%$ & $12 \%$ \\
\hline Primary & $28 \%$ & $40 \%$ & $35 \%$ \\
\hline Secondary or higher & $40 \%$ & $20 \%$ & $53 \%$ \\
\hline
\end{tabular}

companies to keep going. They're putting our whole lives, culture, and environment in danger... and that includes NTI...they need to realize that caribou is our money and economics too.

Hugh Ikoe

Overharvesting was not a widespread concern, but two participants from Qamani'tuaq identified an issue with caribou populations and voiced concern about hunting of the front of the caribou herds as they migrated, a practice the elders condemn. Hunting the front of a herd was said to have the potential to change migration patterns because the caribou that follow the leaders might alter their direction when the leaders were hunted.

Although certain participants, predominantly those in Qamani'tuaq, expressed some concern about caribou populations, the remaining interviewees indicated that the caribou population is fine and should remain as it is, and that any perception of decline in caribou populations was due to the animals' migration. The following comments provide context:

Caribou population is not shrinking but using other areas. Louis Autut (translated) 
They're migratory, every five years we got lots of caribou, but then every few years we get no caribou... animals aren't declining.

\section{Kevin Issaluk}

Mining and barges are pushing animals away, not making them decline, but pushing them away.

\section{Leo Mimialik (translated)}

A participant in Igluligaarjuk and one in Tikirarjuaq, and three participants (19\%) in Qamani'tuaq expressed concern about grizzly bears getting into meat caches and indicated that grizzly bear populations were too high:

Sixty years ago, there never used to be grizzly bear around, now they are all over. Probably two or three time as much as before.

Joe Mautaritnaaq

Higher quotas, polar bear quotas, we need more... grizzly bear, I don't think there is a quota for them, we can kill them if we need to.

Participant 33002

Some participants hunted grizzly bears, and those who expressed concern felt that if a grizzly bear became a problem, it would be destroyed. These participants expressed contentment with management so long as they could continue to hunt the bears and hunters could put down dangerous animals if they needed to.

\section{DISCUSSION}

\section{General Satisfaction with Co-Management}

Perhaps the most important finding of this research is that Inuit in the participating communities were predominantly content with (or indifferent to) wildlife co-management, except for the dissatisfaction in the coastal communities with polar bear management. In other words, in Igluligaarjuk and Tikirarjuaq, resentment and mistrust towards polar bear management do not necessarily apply to the wildlife co-management decision-making system generally. This result is reinforced by results from Qamani'tuaq, which is inland and where concern about polar bear management was not nearly as high. In Qamani'tuaq, attitudes towards the management of all the species were not significantly different, and management was regarded more favourably than unfavourably, although concern about grizzly bear and caribou populations was more pronounced than in the other communities. In addition, in the coastal communities there was a higher overall response rate when participants were asked about polar bear management than when they were asked about other species, indicating its importance to them.
The influence of local communities in decisionmaking in Nunavut may be stronger than anywhere in North America (Gilchrist and Mallory, 2007). The co-management system, which is based on considerable inclusion of local institutions in decision-making, is key to its success and exemplifies many of the ideals described by the principle of subsidiarity (Spicker, 1991; Marshall et al., 2007; Berkes, 2010). Our results indicate that dissatisfaction with polar bear management may be more closely related to dissatisfaction with polar bear management outcomes than with the decision-making process at the territorial level. This finding is a marked contrast to previous predictions that conflicts specific to polar bear management could lead to regulations being ignored or even defied and endanger the entire system of wildlife co-management (Clark et al., 2009).

Our results show that research participants living in the two coastal communities of Igluligaarjuk and Tikirarjuaq on western Hudson Bay do not think the polar bear population there has declined. This position is at odds with most - though, importantly, not all—biological research to date (Stapleton et al., 2014; Lunn et al., 2016). Scientists have attributed more bear sightings and encounters to biophysical changes, as opposed to population changes (Stirling and Parkinson, 2006), an unfortunate dialectic that has profoundly challenged the management of the species in Canada (Clark et al., 2008; Dowsley and Wenzel, 2008; Henri et al., 2010; Peacock et al., 2011). Kotierk (2012) documented findings similar to ours, reporting that the wildlife management issues of greatest concern to people in western Hudson Bay communities were the high number of polar bears and the need to increase or remove the quotas. In Kotierk's study, most respondents indicated there were the "most" polar bears currently and that "fewer" bears would be more desirable. Concern over human vulnerability and safety related to the high number of polar bears has also been reported by Tyrrell (2006) and Nirlungayuk and Lee (2009:137), who explain that Inuit have a different, longerterm "geographic and temporal understanding" of polar bear populations that is not reflected in current quotas.

The disparate positions about polar bear populations held by Inuit and leading scientists discussed above may be compounded by another reason the polar bear quota controversy has not resulted in a solution that is acceptable to Inuit: constraints imposed on polar bear management in Nunavut by international groups and agreements, including the Polar Bear Specialist Group (PBSG) and provisions under the Agreement on the Conservation of Polar Bears, the U.S. Endangered Species Act, and the Convention on International Trade in Endangered Species. Designations and criticism by these organizations have resulted in restrictions in Nunavut and probably propagate Inuit feelings of resentment towards international organizations influencing polar bear management outcomes in Nunavut (Dowsley and Wenzel, 2008; Nirlungayuk and Lee, 2009). For example, the PBSG Resolution Number One states that traditional knowledge only carries weight if it is validated by Western 
science (Clark et al., 2008), and trade restrictions on polar bear parts under the agreements listed above have reduced local economic gain and control related to sport hunting in Nunavut (Clark et al., 2013; Tyrrell and Clark, 2014).

\section{Polar Bear Quotas}

More research participants in Igluligaarjuk and Tikirarjuaq indicated that the polar bear quotas should be increased as opposed to abolished. Although there are some issues related to quotas themselves (Tyrrell, 2009), and over one-third of participants in Tikirarjuaq indicated they would like to see quotas abolished (Table 1), the concept of quotas and the process of deciding on a total allowable harvest and allocating quotas may not cause as much of a problem for these communities as the size of the quotas that are allocated. The existence of quotas may well be a less important contributor to dissatisfaction than quotas that significantly constrain hunting in areas where humans coexist with dangerous large carnivores.

The pressure put on communities by what are felt to be constraining polar bear quotas is magnified when polar bears killed in defence are counted as part of the allotted quota and reduce the bears available for subsistence or sport hunting (Nirlungayuk and Lee, 2009). According to some study participants, concern about defence kills that count as part of the quota is becoming more acute with the increase in polar bear-human conflicts (Clark et al., 2013). Further research into factors contributing to increased polar bear conflicts would be useful. Similarly, Clark and Slocombe (2011) report that when there were quotas on grizzly bear around Qamani'tuaq, there had been concerns about the requirement that problem bears shot should count towards quotas; people felt that communities were paying twice. However, our data are more recent by 10 years and indicate an apparent increase in satisfaction with grizzly bear management. This increase in satisfaction may be due to the intervening removal of quotas on grizzlies, enabling hunters to deal with problem bears if necessary without fear of penalties.

A large proportion of participants who indicated that quotas should be abolished were over 60 years old with no secondary education (Table 2). Ray (2011) documented a similar pattern among Koyukon people in interior Alaska: elders put less trust in science and non-Koyukon resource management practices than did younger generations. This difference may suggest that the quota system makes more sense to younger generations, whose education and experience differ from those of people who may have been educated on the land. Further elucidation of this relationship would be useful. This relationship may be particularly important to co-management success because the guidance of elders is highly respected and influential in Nunavut. Consequently, generating support for decisions by elders at the community level would probably increase acceptance of wildlife management decisions by Inuit and build trust in the institution of co-management.
Dissatisfaction with the concept of quotas expressed predominantly by some of the older participants in this study is probably related to feelings that they are losing control over harvesting. Dowsley (2009) and Tyrrell (2009) identified concerns regarding quotas in Nunavut that echoed those of participants in this study. Polar bears are often treated with great respect, so quotas and hunting for sport may be considered unethical or disrespectful to the bear. Nontraditional hunting is believed to run the risk of angering the bear so that it leaves or attacks. Quotas also turn polar bears into property and therefore may restrict others from hunting. Although communities have various ways of sharing harvested animals and profits, a quota system disrupts a culture where a communal resource was hunted based on need, or when bears presented themselves. One participant indicated that more bears may actually be killed because of quotas, suggesting that when there is a quota, people may take bears whenever they get the chance until the quota is used up, instead of taking bears only at optimal times and in optimal conditions when there is no quota.

\section{Caribou Populations}

Perceived changes in caribou populations, predominantly identified in Qamani'tuaq, were mainly attributed to a changing climate or to caribou staying away from settled areas and being displaced by aircraft, mining, and exploration activities. Overharvesting was not a widespread concern, although it was noted that some hunters may be ignoring elders' advice and hunting the front of the caribou herds, thereby potentially changing migration patterns. The limited access to sea mammals in Qamani'tuaq makes caribou a very important resource. Concern about the caribou population in the area and the fact that hunters may need to travel farther to find the animals may stem from a number of factors: the value of the caribou to the community, increased resource extraction activity, and the fact that the town is larger and busier than the coastal communities in this study. This hypothesis is supported by the majority of the participants, who indicated that the caribou population was doing well. Many of these participants said that if caribou populations were perceived to be declining, this was because the animals were migrating to where the food was and feeding in other areas.

\section{Study Limitations}

This research represents the opinions of Inuit interviewed in the communities of Igluligaarjuk, Qamani'tuaq, and Tikirarjuaq, Nunavut, Canada. The participants in this study were selected through consultation with the HTO of each community, so as to include a variety of participants who were knowledgeable about the proposed subject matter. Therefore, results may not be representative of the overall community but reflect the opinions of a subset of people who are highly engaged in subsistence activities and wildlife management, as well as elders and community leaders. 
We note that in research based on the perspectives of participants, the reliability of findings may be questioned. Collings (2009) describes two such risks that are relevant here. First, the researcher assumes the participant is interested and willing to help, and therefore gives reliable information. Second, information may be misinterpreted. Given the intensity and enthusiasm with which most participants discussed their opinions about animals (especially polar bears) and management, we believe the information given by participants on these topics is as accurate from their perspective as is possible with frequent Inuktitut-English translation. In addition, the results have been communicated at formal presentations in the communities to HTOs, interested participants, and community members, who confirmed its accuracy and representativeness.

\section{CONCLUSION}

Our results suggest that the Nunavut wildlife co-management system is quite functional. Apart from their concerns about polar bear management in Igluligaarjuk and Tikirarjuaq and about caribou populations in Qamani'tuaq, Inuit in these communities are largely content with the current functioning of the wildlife co-management regime. While resentment about what are viewed as constraining polar bear quotas exists, this research indicates that it is directed at polar bear management and does not taint attitudes towards the entire wildlife co-management system. Study participants see the quotas as too low for the current polar bear population, constraining them from shooting bears in potentially hazardous situations and endangering community members. Potential consequences of such resentment are real and could result in a reduced willingness to cooperate with polar bear management, though it is reassuring that it appears unlikely to impact cooperation with co-management as a whole.

The wildlife co-management arrangement in Nunavut has the potential to contribute to polar bear management decisions that represent local interests and are more acceptable to all stakeholders to such an extent as is possible under constraints imposed by international agreements. Indeed, community representatives' compartmentalization of the frustration over polar bear controversies indicates impressive political maturity. Such sophistication reinforces Rodon's (1998) argument that co-management should not be an attempt to co-opt Inuit into a bureaucratic relationship with the government, but can be an inclusive process of governance, actively shaped by the people involved. The next step is cooperation and finding common ground among international organizations involved in polar bear conservation and Inuit in Nunavut who coexist with more than half of the world's polar bear sub-populations.

\section{APPENDIX 1: Questions from the TUNDRA Interview Guide}

25. Do you think the population of the following species is too low or too high or should remain as is? (population of the following species should be increased, decreased, or remain as is? $)(1=$ too low [increase], $2=$ decrease [too high], $3=$ remain as is)

For elders: are the populations of the different animals here too high or too low or just right? Then break it down.

26. Are the following animals managed successfully (Yes) or unsuccessfully (No)? Partly successfully (Partly)? For elders: should anything be done to change the population levels of these animals or change how animals act? (may not understand the term management)

Resource
Caribou
Wolf
Grizzly bear
Muskox
Polar bear
Wolverine
Arctic fox
Hare
Ptarmigan
Geese
Duck
Comments:

44a) What is your opinion about large carnivores like polar bears, grizzly bears, wolves, and wolverines in relation to your community (dangerous, a nuisance, not an issue)?

b) Do laws and regulations affect how you use and control large carnivores? How?

c) Is there anything you would change about how these animals are managed?

\section{ACKNOWLEDGMENTS}

This work was supported by the circumpolar research projects TUNDRA (Research Council of Norway) and CONNECT (Belmont Forum) based at the University of Tromsø - The Arctic University of Norway, the Social Sciences and Humanities Research Council of Canada, the Canadian Polar Commission (now Polar Knowledge Canada) Northern Scientific Training Program, and the School of Environment and Sustainability at the University of Saskatchewan. We thank the Aqigiq, Issatiq, and Baker Lake HTOs as well as all the research participants for their interest and willingness to share information. Special thanks are owed to the following research participants, HTO managers, translators, and others from Nunavut who contributed to this 
research and wished to be acknowledged: Barney Aggark, Mark Amarok, Jacinthe Amarok, Charles Issaluk, Louis Autut, Joseph Issaluk, Kimmy Krako, Casimir Kriterdluk, Theresa Kukkiak, Mark Papak, Eli Kimmaliardjuk, Kevin Issaluk, Elizabeth Papak, Pauline Kadjuk, Harry Aggark, Tim Angotingoar, Jayko Kimmaliardjuk, Leo Mimialik, MaryAnn Sissak, Douglas Aggark, Leah Pupik, Irene Tiktaalaaq, John Nukik Sr., Thomas Qaqimat, Thomas Sevoga, Timothy Evviok, Thomas Anirniq, Winnie Ikinilik, Jamie Seeteenak, Anson Kigusiutnar, Nancy Aupaluktuq, William Scottie, Joseph Mautaritnaaq, Hugh Ikoe, Peter Owingayak, Joan Scottie, Eva Voisey, Andrew Alikashuak, Mary Nangmalik, Sam Arualak, Lewis Voisey, Billy Adjuk, Jackie Napagok, Lisa Jones, Solomon Sr. Voisey, Roy Kriterdluk, Chris Jones, Jenny Enuapik, Robert Enuapik, and Bobby Joe Ulurksit.

\section{REFERENCES}

ACUNS (Association of Canadian Universities for Northern Studies). 2003. Ethical principles for the conduct of research in the North. Ottawa: ACUNS.

http:/acuns.ca/wp-content/uploads/2010/09/EthicsEnglish march2003.pdf

Armitage, D., and Clark, D. 2005. Issues, priorities and research directions for oceans management in Canada's North. In: Berkes, F., Huebert, R., Fast, H., Manseau, M., and Diduck, A., eds. Breaking ice: Renewable resource and ocean management in the Canadian North. Calgary, Alberta: Arctic Institute of North America and University of Calgary Press. 337-362.

Berkes, F. 2010. Devolution of environment and resources governance: Trends and future. Environmental Conservation 37(4):489-500.

https://doi.org/10.1017/S037689291000072X

Berkes, F., Colding, J., and Folke, C., eds. 2003. Navigating social-ecological systems: Building resilience for complexity and change. Cambridge: Cambridge University Press.

Brannen, J. 2005. Mixing methods: The entry of qualitative and quantitative approaches into the research process. International Journal of Social Research Methodology 8(3):173 - 184. https://doi.org/10.1080/13645570500154642

Brondizio, E.S., Ostrom, E., and Young, O.R. 2009. Connectivity and the governance of multilevel socio-ecological systems: The role of social capital. Annual Review of Environment and Resources 34:253-278. https://doi.org/10.1146/annurev.environ.020708.100707

Clark, D.A., and Slocombe, S. 2011. Adaptive co-management and grizzly bear-human conflicts in two northern Canadian Aboriginal communities. Human Ecology 39(5):627-640. https://doi.org/10.1007/s10745-011-9423-x

Clark, D.A., Lee, D.S., Freeman, M.M.R., and Clark, S.G. 2008. Polar bear conservation in Canada: Defining the policy problems. Arctic 61(4):347-360.

https://doi.org/10.14430/arctic43

Clark, D.A., Tyrrell, M., Dowsley, M., Foote, L., Freeman, M.M.R., and Clark, S.G. 2009. Polar bears, climate change, and human dignity: Seeking integrative conservation policies.
In: Freeman, M.M.R., and Foote, L., eds. Inuit, polar bears, and sustainable use: Local, national, and international perspectives. Edmonton, Alberta: Canadian Circumpolar Institute Press. 233-242.

Clark, D.A., Meek, C., Cheechoo, J., Clark, S., Foote, A.L., Lee, D., and York, G. 2013. Polar bears and CITES: A rejoinder to Parsons and Cornick. Marine Policy 38:365-368. https://doi.org/10.1016/j.marpol.2012.06.014

Collings, P. 2009. Participant observation and phased assertion as research strategies in the Canadian Arctic. Field Methods 21(2):133-153.

https://doi.org/10.1177/1525822X08330260

Creswell, J.W. 1998. Qualitative inquiry and research design: Choosing among five traditions. Thousand Oaks, California: Sage.

Dale, A., and Armitage, D. 2011. Marine mammal co-management in Canada's Arctic: Knowledge co-production for learning and adaptive capacity. Marine Policy 35(4):440-449. https://doi.org/10.1016/j.marpol.2010.10.019

Dowsley, M. 2009. Inuit-organised polar bear sport hunting in Nunavut Territory, Canada. Journal of Ecotourism $8(2): 161-175$.

https://doi.org/10.1080/14724040802696049

Dowsley, M., and Wenzel, G. 2008. "The time of the most polar bears": A co-management conflict in Nunavut. Arctic 61(2):177- 189 .

https://doi.org/10.14430/arctic56

Ewins, P.J., Clark, D.A., York, G., Main, J., Sahanatien, V., and Hedman, D. 2016. Hudson Bay Front-Line Operators Workshop (FLOW) on Polar Bear-Human Conflict Reduction Measures, 21-24 March 2016. Unpubl. report. Toronto, Ontario: WWFCanada. 47 p.

https://arcticsustainability.files.wordpress.com/2017/03/flow report_2016.pdf

Fabricius, C., Folke, C., Cundhill, G., and Schultz, L. 2007. Powerless spectators, coping actors, and adaptive comanagers: A synthesis of the role of communities in ecosystem management. Ecology and Society 12(1): 29. https://doi.org/10.5751/ES-02072-120129

Fauchald, P., Hausner, V.H., Schmidt, J.I., and Clark, D.A. 2017. Transitions of social-ecological subsistence systems in the Arctic. International Journal of the Commons 11(1):275-329. https://doi.org/10.18352/ijc.698

Frels, R.K., and Onwuegbuzie, A.J. 2013. Administering quantitative instruments with qualitative interviews: A mixed research approach. Journal of Counseling \& Development 91(2):184-194. https://doi.org/10.1002/j.1556-6676.2013.00085.x

Gilchrist, G., and Mallory, M.L. 2007. Comparing expert-based science with local ecological knowledge: What are we afraid of? Ecology and Society 12(1): r1. https://doi.org/10.5751/ES-01972-1201r01

Glikman, J.A., Vaske, J.J., Bath, A.J., Ciucci, P., and Boitani, L. 2012. Residents' support for wolf and bear conservation: The moderating influence of knowledge. European Journal of Wildlife Research 58(1):295-302. https://doi.org/10.1007/s10344-011-0579-x 
Heberlein, T.A. 2012. Navigating environmental attitudes. New York: Oxford University Press. https://doi.org/10.1093/acprof:oso/9780199773329.001.0001

Henri, D., Gilchrist, H.G., and Peacock, E. 2010. Understanding and managing wildlife in Hudson Bay under a changing climate: Some recent contributions from Inuit and Cree ecological knowledge. In: Ferguson, S.H., Loseto, L.L., and Mallory, M.L., eds. A little less Arctic: Top predators in the world's largest northern inland sea, Hudson Bay. New York: Springer. 267-289. https://doi.org/10.1007/978-90-481-9121-5_13

Kotierk, M. 2012. Public and Inuit interests, western Hudson Bay polar bears and wildlife management: Results of a public opinion poll in western Hudson Bay communities. Iqaluit: Department of Environment, Government of Nunavut. http://gov.nu.ca/sites/default/files/whb pop final report.pdf

Kunuk, Z., and Mauro, I.M. 2010. Inuit knowledge and climate change [video recording]. Montreal, Quebec: IsumaTV. http://www.isuma.tv/hi/en/inuit-knowledge-and-climatechange/movie

Lunn, N.J., Servanty, S., Regehr, E.V., Converse, S.J., Richardson, E., and Stirling, I. 2016. Demography of an apex predator at the edge of its range: Impacts of changing sea ice on polar bears in Hudson Bay. Ecological Applications 26(5):1302 - 1320. https://doi.org/10.1890/15-1256

Mallory, M.L., Fontaine, A.J., Akearok, J.A., and Johnston, V.H. 2006. Synergy of local ecological knowledge, community involvement and scientific study to develop marine wildlife areas in eastern Arctic Canada. Polar Record 42(3):205-216. https://doi.org/10.1017/S0032247406005481

Marshall, N.A., Fenton, D.M., Marshall, P.A., and Sutton, S.G. 2007. How resource dependency can influence social resilience within a primary resource industry. Rural Sociology 72(3):359-390. https://doi.org/10.1526/003601107781799254

Nirlungayuk, G., and Lee, D.S. 2009. A Nunavut Inuit perspective on western Hudson Bay polar bear management and the consequences for conservation hunting. In: Freeman, M.M.R., and Foote, L., eds. Inuit, polar bears, and sustainable use: Local, national and international perspectives. Edmonton: Canadian Circumpolar Institute Press. 135-142.

Peacock, E., Derocher, A.E., Thiemann, G.W., and Stirling, I. 2011. Conservation and management of Canada's polar bears (Ursus maritimus) in a changing Arctic. Canadian Journal of Zoology 89(5):371-385. https://doi.org/10.1139/z11-021

Putnam, R.D., Leonardi, R., and Nanetti, R.Y. 1994. Making democracy work: Civic traditions in modern Italy. Princeton: Princeton University Press.

Ray, L. 2011. Using Q-methodology to identify local perspectives on wildfires in two Koyukon Athabascan communities in rural Alaska. Sustainability: Science, Practice and Policy $7(2): 18-29$.

https://doi.org/10.1080/15487733.2011.11908070
Robinson, O.C. 2014. Sampling in interview-based qualitative research: A theoretical and practical guide. Qualitative Research in Psychology 11(1):25-41.

https://doi.org/10.1080/14780887.2013.801543

Rodon, T. 1998. Co-management and self-determination in Nunavut. Polar Geography 22(2):119-135. https://doi.org/10.1080/10889379809377641

Spicker, P. 1991. The principle of subsidiarity and the social policy of the European Community. Journal of European Social Policy 1(1):3-14. https://doi.org/10.1177/095892879100100102

Stapleton, S., Atkinson, S., Hedman, D., and Garshelis, D. 2014. Revisiting western Hudson Bay: Using aerial surveys to update polar bear abundance in a sentinel population. Biological Conservation 170:38-47.

https://doi.org/10.1016/j.biocon.2013.12.040

Statistics Canada. 2017. Census profile, 2016 Census. http://www12.statcan.gc.ca/census-recensement/2016/dp-pd/ prof/index.cfm?Lang=E

Stirling, I., and Parkinson, C.L. 2006. Possible effects of climate warming on selected populations of polar bears (Ursus maritimus) in the Canadian Arctic. Arctic 59(3):261 - 275. https://doi.org/10.14430/arctic312

Suluk, T.K., and Blakney, S.L. 2008. Land claims and resistance to the management of harvester activities in Nunavut. Arctic 61(Suppl. 1):62-70.

https://oi.org/10.14430/arctic102

TUNDRA. 2018. Drivers of change in circumpolar tundra ecosystems.

http://site.uit.no/tundra/

Tyrrell, M. 2006. More bears, less bears: Inuit and scientific perceptions of polar bear populations on the west coast of Hudson Bay. Études/Inuit/Studies 30(2):191 - 208. https://doi.org/10.7202/017571ar

- 2007. Sentient beings and wildlife resources: Inuit, beluga whales and management regimes in the Canadian Arctic. Human Ecology 35(5):575-586. https://doi.org/10.1007/s10745-006-9105-2

2009. West Hudson Bay polar bears: The Inuit perspective. In: Freeman, M.M.R., and Foote, L., eds. Inuit, polar bears, and sustainable use: Local, national and international perspectives. Edmonton: Canadian Circumpolar Institute Press. 95-110.

Tyrrell, M., and Clark, D.A. 2014. What happened to climate change? CITES and the reconfiguration of polar bear conservation discourse. Global Environmental Change $24: 363-372$.

https://doi.org/10.1016/j.gloenvcha.2013.11.016

White, G. 2009. Governance in Nunavut: Capacity vs. culture? Journal of Canadian Studies/Revue d'études canadiennes 43(2):57-81.

https://doi.org/10.3138/jcs.43.2.57

Zajac, R.M., Bruskotter, J.T., Wilson, R.S., and Prange, S. 2012. Learning to live with black bears: A psychological model of acceptance. Journal of Wildlife Management 76(7): $1331-1340$.

https://doi.org/10.1002/jwmg.398 